\title{
Tumour-infiltrating lymphocytes as a prognostic and tamoxifen predictive marker in premenopausal breast cancer: data from a randomised trial with long- term follow-up
}

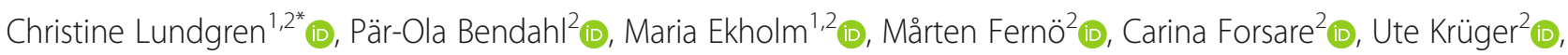
Bo Nordenskjöld ${ }^{3}$ (D) Olle Stål ${ }^{3}$ (D) and Lisa Rydén ${ }^{4,5}$ (D)

\begin{abstract}
Background: Tumour-infiltrating lymphocytes (TILs) are of important prognostic and predictive value in human epidermal growth factor receptor 2-positive (HER2+) breast cancer (BC) and triple-negative breast cancer (TNBC), but their clinical relevance in oestrogen receptor-positive/HER2-negative (ER+/HER2-) remains unknown. The primary study aim was to analyse the prognostic effect of TILs on the BC-free interval (BCFi) in premenopausal patients stratified by BC subtypes. The secondary aim was to investigate if TILS are predictive of tamoxifen (TAM) benefit.

Methods: Archival tissues from primary breast tumours were collected from patients from the SBIl:2pre trial, in which 564 premenopausal women were randomised to 2 years of adjuvant TAM or no systemic treatment, regardless of hormone receptor status. TILs were scored on whole tissue sections from 447 patients with available ER status. Tumours were divided into ER+/HER2-, HER2+ and TNBC subtypes by immunohistochemistry and in situ hybridisation. The prognostic value of TILs was analysed in systemically untreated patients $(n=221)$; the predictive information was investigated in the ER+ subgroup $(n=321)$ by cumulative incidence curves and Cox regression analyses. The median follow-up was 28 years.

Results: High ( $\geq 50 \%$ ) infiltration of TILs was a favourable prognostic factor in terms of BCFi (univariable analysis: hazard ratio BCFi $_{(}\left(H_{B C F i}\right) 0.40 ; 95 \%$ confidence interval $\left.(C l) 0.22-0.71 ; P=0.002\right)$. Similar effects were observed across all BC subtypes. The effect of adjuvant TAM was stronger in patients with ER+ tumours and TILs $<50 \%$ (HRRCFi $0.63 ; 95 \%$ $\mathrm{Cl} 0.47-0.84 ; P=0.002)$ than in patients with high immune infiltration $(\geq 50 \%)\left(\mathrm{HR}_{\mathrm{BCF}} \mathrm{0.84} ; 95 \% \mathrm{Cl}(0.24-2.86) ; P=0.77\right)$. However, evidence for differential effects of TAM in categories of TILs, i.e. interaction, was weak.

(Continued on next page)
\end{abstract}

\footnotetext{
* Correspondence: christine.lundgren@med.lu.se

'Department of Oncology, Region Jönköping County, Jönköping, Sweden

${ }^{2}$ Department of Clinical Sciences Lund, Division of Oncology, Lund University, Lund, Sweden

Full list of author information is available at the end of the article
}

(C) The Author(s). 2020 Open Access This article is licensed under a Creative Commons Attribution 4.0 International License, which permits use, sharing, adaptation, distribution and reproduction in any medium or format, as long as you give appropriate credit to the original author(s) and the source, provide a link to the Creative Commons licence, and indicate if changes were made. The images or other third party material in this article are included in the article's Creative Commons licence, unless indicated otherwise in a credit line to the material. If material is not included in the article's Creative Commons licence and your intended use is not permitted by statutory regulation or exceeds the permitted use, you will need to obtain permission directly from the copyright holder. To view a copy of this licence, visit http://creativecommons.org/licenses/by/4.0/ The Creative Commons Public Domain Dedication waiver (http://creativecommons.org/publicdomain/zero/1.0/) applies to the data made available in this article, unless otherwise stated in a credit line to the data. 


\begin{abstract}
(Continued from previous page)
Conclusions: We demonstrate a long-term favourable prognostic value of high infiltration of TILs in a cohort of premenopausal BC patients and the positive prognostic effect was extended to the ER+/HER2- subgroup. A beneficial effect of TAM in ER+ patients was observed in patients with tumours of low TIL infiltration, but evidence for a treatment predictive effect was weak.
\end{abstract}

Trial registration: This trial is registered in the ISRCTN database, trial ID: ISRCTN12474687.

Keywords: Breast cancer, TILs, Prognosis, Tamoxifen, Premenopausal, Predictive, Biomarker

\section{Background}

The breast cancer $(\mathrm{BC})$ subtypes, as determined by either gene expression analysis or surrogate immunohistochemical (IHC) markers (oestrogen receptor (ER), progesterone receptor (PR), human epidermal growth factor receptor 2 (HER2), proliferation marker (Ki67), and Nottingham histological grade (NHG), have different prognostic and predictive characteristics $[1,2]$. In addition, they show differences in immune biology and mutational load; for example, the HER2-positive (HER2+) BC and triple-negative breast cancer (TNBC) subtypes have a higher lymphocyte infiltration compared with ER-positive/HER2-negative (ER+/HER2-) tumours [3] and moreover, a higher mutational load is observed in ER-negative (ER-) tumours than ER+ tumours [4].

Lymphocyte-predominant BC (LPBC) are tumours with a higher proportion of immune cell infiltration than invasive tumour cells [5]. An abundance of tumour-infiltrating lymphocytes (TILs) has been shown to indicate good prognosis, particularly for the HER2+ and TNBC subtypes [6-9]. In HER2+ tumours, high level of TILs has been linked to different responsiveness to chemotherapy and increased efficacy of adjuvant trastuzumab treatment $[3,7$, 10]. However, data on the influence of lymphocyte infiltration on prognoses and therapy prediction in patients with ER+/HER2- tumours are sparse $[3,6,11]$.

In TNBC and HER2+ BC, LPBC predict pathological complete response ( $\mathrm{pCR}$ ) after neoadjuvant chemotherapy $[6,12]$. This association has also been reported in the hormone receptor-positive /HER2- subgroup, in which a high level of TILs is associated with pCR $[6,13]$. However, results regarding the ability of TILs to predict the effect of neoadjuvant endocrine therapy are sparse $[14,15]$. In addition, except for some studies of TIL phenotypes, there are no reports on TILs as predictors for adjuvant endocrine therapy in the ER+/HER2subgroup.

Despite the beneficial effects of adjuvant tamoxifen (TAM) in ER+ BC [16], some patients experience late recurrences after diagnosis [17]. Currently, no markers have been identified that predict late $\mathrm{BC}$-related events, and any potential predictors must be investigated in trials with long-term follow up. The SBII:2pre randomised controlled trial included premenopausal women that received 2 years of adjuvant TAM or no adjuvant systemic therapy during 1984-1991, irrespective of hormone receptor status. We have previously reported the beneficial effect of 2 years of TAM in this trial based on long-term ( 30 years) outcome [18]. This cohort provides an excellent basis for further studies on the prognostic effect and predictive value of TILs in relation to adjuvant TAM therapy in premenopausal patients for whom TAM is still a commonly recommended endocrine therapy $[19,20]$.

The primary aim of this study was to investigate the prognostic value of high infiltration of TILs in premenopausal patients across different $\mathrm{BC}$ subtypes including ER+/HER2- BC from the SBII:2pre randomised controlled trial. Our secondary aim was to investigate TILs as a predictive marker for TAM efficacy in the ER+ subgroup.

\section{Methods}

\section{Patients and study cohorts}

The patients in this study participated in the SBII:2pre study and details of the study have been previously presented [18, 21, 22]. Briefly, during 1984-1991, 564 premenopausal women with stage II invasive BC (UICC TNM, third edition (1982)) were randomised between 2 years of adjuvant TAM or no systemic treatment. Two coordinating centres including 20 hospitals participated in the study: the South Eastern (Oncological Centre Lund) and Southern (Oncological Centre Linköping) Health Care Regions. Four patients were excluded in the latest update of the study due to protocol violations found by scrutiny of the patient records [18]. Among the included 560 patients, 284 were randomised to the control arm and 276 to the TAM treatment arm (Fig. 1). In the present study, the prognostic value of TILs was evaluated in patients allocated to no systemic therapy with tumours successfully scored for TILs and available IHC/in situ hybridisation (ISH) data for defining BC subtypes. All patients with ER+ tumours and successfully annotated TILs were included in the assessment of the prediction of TAM efficacy (Fig. 1).

\section{Follow-up data}

Data on invasive distant, regional and local recurrence, contralateral $\mathrm{BC}, \mathrm{BC}$-related death and death due to 


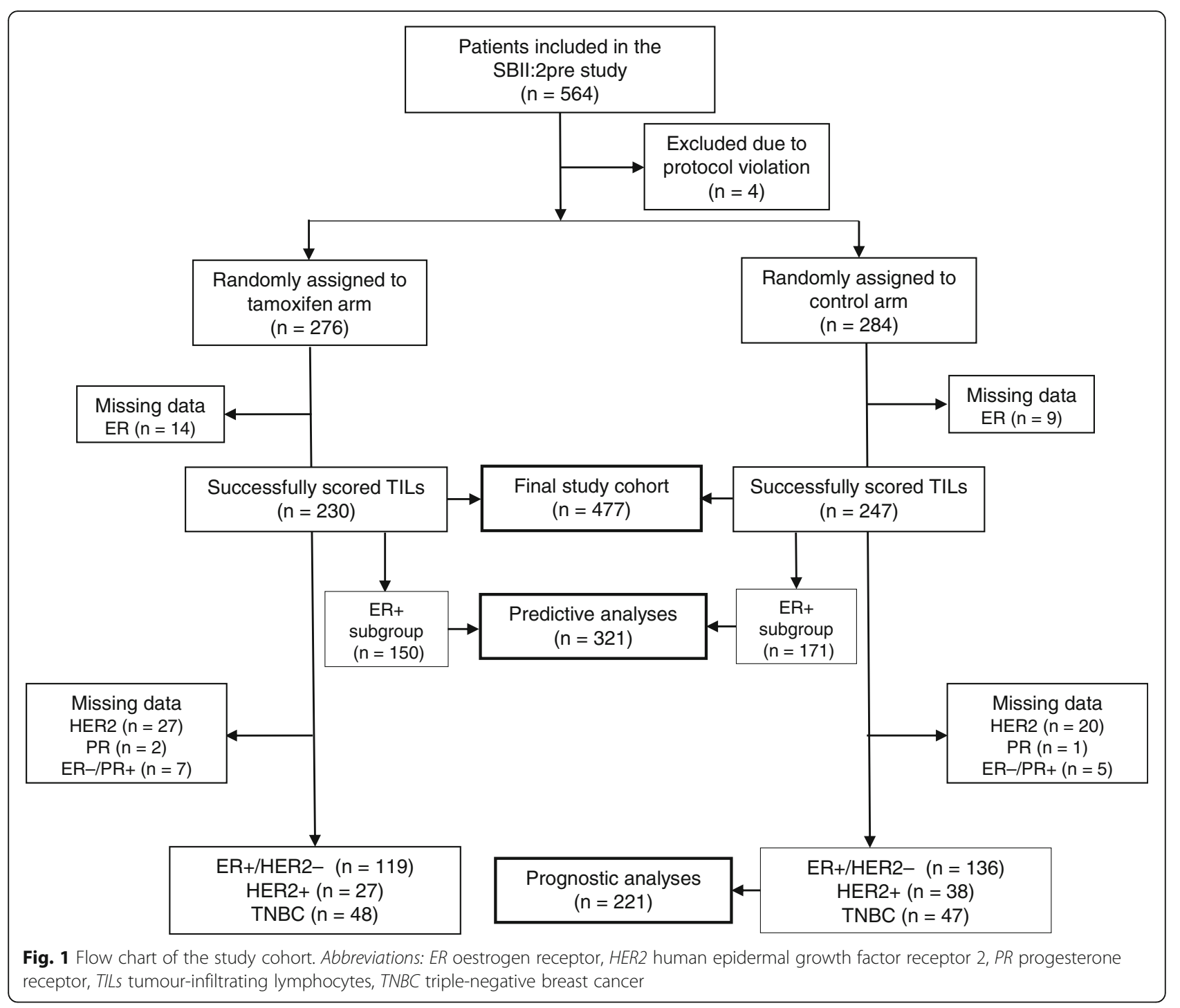

other causes were determined based on a thorough review of all medical records and the Swedish Cause of Death Register as previously described [18].

\section{Tumour characteristics and microscopic assessments of TILs and lymphovascular invasion (LVI)}

Tissue microarrays were used for assessment of ER, PR, Ki67 and HER2. ER and PR were assessed by IHC and ER/ PR-positivity was defined as tumours with $>10 \%$ stained nuclei according to Swedish Guidelines [23]. Data on both IHC and the cytosol-based method were available; for tumours with missing IHC data, the results from the original cytosol-based methods were used (ER: $n=32$; PR: $n=46$ ). Ki67 was assessed as a categorical variable $(\leq 10 \%, 11-$ $25 \%, \geq 26 \%$ ) [24]. Tumours were classified as HER2+ either by HER 2 amplification by fluorescent ISH $(n=$ 54 ) or by HER2 $3+$ as assessed by IHC in cases in which ISH data were missing $(n=12)$. Histological grade was evaluated as NHG according to Elston et al. [25]. The tumours were stratified into three subtypes based on IHC and ISH markers: ER+/HER2-, HER2+ (irrespective of ER status) and TNBC (ER-/PR-/HER2-).

Archival formalin-fixed paraffin-embedded tissues from breast tumours in the SBII:2pre trial were collected from seven regional biobanks and stained by haematoxylin-eosin $(n=520)$. Of these, 488 were available for TIL scoring and 486 for assessment of LVI. The scoring of TILs was performed according to the definition by the ImmunoOncology International TILs Working Group, in which stromal TILs (referred to as TILs in the current study) are defined as the proportion of the stromal area containing infiltration of lymphocytes with no direct contact with invasive tumour cells [5]. Microscopic assessment was performed by a board-certified breast pathologist (Ute Krüger) blinded to the patient characteristics and outcomes. TILs were assessed under a light microscope (BX63F, Olympus, 
Japan) with a magnification of 40 and 100 (if necessary, 200). Tumours were categorised into the following groups based on TIL infiltration: $<10 \%, 10-49 \%, 50-74 \%$ and $\geq$ $75 \%$. In the prognostic analyses, the two latter groups were merged into one category (high), and the three groups were then denoted as low, intermediate and high. Tumours with TILs $\geq 50 \%$ were also defined as LPBC and tumours with low/intermediate TILs $(<50 \%)$ were defined as nonLPBC in the predictive analyses. Photomicrographs of the different TIL categories are shown in Fig. 2.

According to the Swedish pathological guidelines, LVI was defined as present when tumour cells in cavities lined with endothelium (not by IHC endothelial markers) were verified in the peritumour area [23]. Patient and tumour characteristics have been reported previously $[18,21,22]$ and are listed in Additional file 1, stratified by tumours with and without scored TILs.

\section{Statistical analyses}

Differences in distribution between clinico-pathological variables and TILs were analysed by chi2 test and chi2 test for trend. The primary endpoint was $\mathrm{BC}$-free interval (BCFi), defined as the first event of local, regional or distant recurrence, contralateral $\mathrm{BC}$ (invasive or ductal cancer in situ (DCIS)) or BC-related death. The association with overall survival (OS) was also explored. The data cut-off date for events was November 30, 2016.
The cumulative incidence of $\mathrm{BC}$-related events as a function of follow-up time was estimated and compared among patient subgroups to handle the problem with competing risks. To facilitate the comparison of results for the two endpoints, $\mathrm{BCFi}$ and OS, cumulative incidence, which is the same as one minus the Kaplan-Meier estimate, was also used for the endpoint death from all causes. The log-rank test was used to evaluate the evidence for difference between cumulative incidence curves and the trend version of the test was used for comparison with more than two ordered groups. Hazard ratios (HR) were calculated by Cox regression analyses, stratified by region.

The follow-up was censored in the analysis of BCFi if a patient died from a cause that was not BC-related without a preceding $\mathrm{BC}$ event included in the definition of an event for BCFi. Hence, the estimated HRs for BCFi in this cause-specific Cox regression analysis should be interpreted in an imaginary world where all other causes of death have been eliminated. In the predictive multivariable analyses, PR status was omitted due to collinearity with ER status. A Cox model with a term for interaction between TIL subgroup (LPBC vs. non-LPBC) and TAM was fitted to evaluate the evidence for differential effect of TAM in the two TIL subgroups. Exclusion of the seven cases with mostly DCIS in addition to microinvasion did not change the results, and these were therefore included in the analyses.
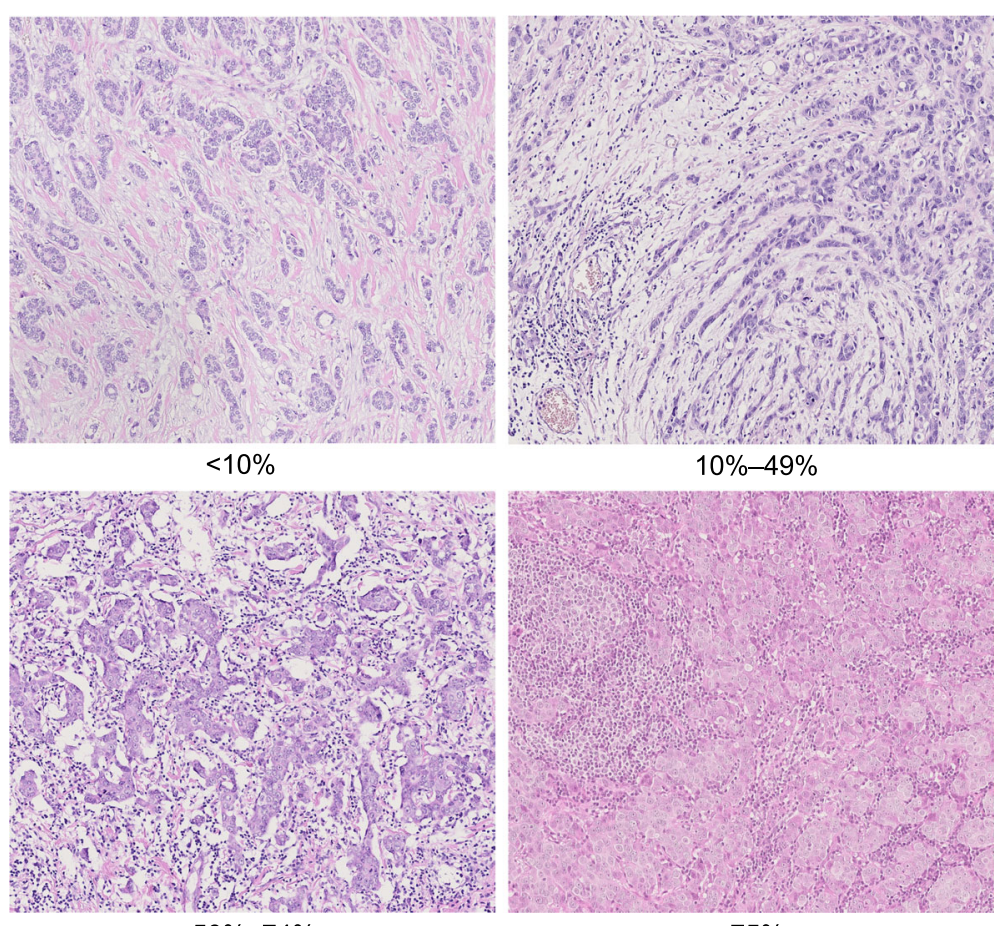

$\geq 75 \%$

Fig. 2 Variable degree of lymphocytic infiltration on haematoxylin and eosin-stained tumour sections ( $\times 200$ magnification) 
HRs are presented with 95\% confidence intervals (CIs). All statistical tests are two-sided. The statistical calculations were performed with IBM SPSS Statistics, Version 25.0 (IBM Corp., Armonk, NY, USA), and the cumulative incidence curves were drawn using STATA, Version 16.1 (StataCorp LLC, College Station, TX, USA).

\section{Results}

Tumours were successfully scored for TILs into the following groups: low (<10\%), intermediate (10-49\%) and high $(\geq 50 \%)$ groups. For tumours with available ER status $(n=477)$, approximately half of the tumours were in the low group $(52 \%, 248 / 477)$, while $33 \%(157 / 477)$ were in the intermediate group and 15\% (72/477) were in the high group. There were a total of 321 ER+ tumours and $320 \mathrm{PR}+$ tumours. After exclusion of tumours with missing HER2 and/or PR status as well as $\mathrm{ER}-/ \mathrm{PR}+$ tumours (considered an inconclusive subgroup $[26,27])$, the tumours were classified as follows: ER+/ HER $2-, 61 \%(n=255 / 415)$; HER $2+, 16 \%(n=65 / 415)$; and TNBC, $23 \%(n=95 / 415)$ (Fig. 1). There were 153 $\mathrm{BC}$-related events in the control-arm during the followup. The number of BC-related events in the control and TAM group for prediction analyses (ER+ tumours) were 119 and 81, respectively. The median follow-up for patients without any BC-related events was 28 years.

\section{Distribution of TILs in relation to clinicopathological variables}

The distribution of TILs in relation to patient and tumour characteristics in the study cohort $(n=477)$ is presented in Table 1. A high proportion of immune cell infiltration was associated with younger age, high histological grade, ER-, PR- and HER2+ status, high Ki67 and medullary histological type. None of the lobular tumours had high infiltration of TILs. The frequency of high TILs in ER+/ HER2-, HER2+ and TNBC subgroups was $6 \%(n=16 /$ 257), $24 \%(n=16 / 66)$ and $35 \%(n=33 / 95)$, respectively. The frequency of low TILs was $69 \%(n=176 / 257), 33 \%$ $(n=22 / 66)$ and $21 \%(n=20 / 95)$, respectively.

\section{TILs as a prognostic marker for BC events}

The prognoses in terms of BCFi and OS stratified by the three TIL categories (low, intermediate, high) are displayed in Figs. $3 \mathrm{a}-\mathrm{d}$ and $4 \mathrm{a}-\mathrm{d}$, respectively. The prognostic value of TILs was evaluated for all patients included in the control arm $(n=221)$ stratified by subtypes (ER+/HER2-, $n=136$; HER2+, $n=38$; and TNBC, $n=47$ ) (Fig. 1). All patients with high TILs, irrespective of BC subtype, had improved prognosis compared with patients with low TILs $\left(\mathrm{HR}_{\mathrm{BCFi}} 0.40 ; 95 \%\right.$ CI $0.22-0.71$; $P=0.002$, and $\mathrm{HR}_{\mathrm{OS}} 0.52 ; 95 \%$ CI $0.29-0.95 ; P=0.03$ ) (Table 2). This was true also in multivariable analysis adjusting for age, nodal status, tumour size, histological grade, ER, PR, HER2 and LVI $\left(\mathrm{HR}_{\mathrm{BCFi}} 0.22 ; 95 \% \mathrm{CI}\right.$ $0.11-0.43 ; P<0.001$ and $\mathrm{HR}_{\mathrm{OS}} 0.23 ; 95 \% \mathrm{CI} 0.11-0.48$; $P<0.001)$. The univariable prognostic effect of high vs. low TILs was essentially the same in patients with ER+/ HER2 - tumours ( $\mathrm{HR}_{\mathrm{BCFi}}$ 0.40; 95\% CI 0.14-1.09; $P=$ $0.07)$ as well as in HER2+ $\left(\mathrm{HR}_{\mathrm{BCFi}} 0.28 ; 95 \%\right.$ CI $0.06-$ $0.97 ; P=0.05)$ and TNBC tumours $\left(\mathrm{HR}_{\mathrm{BCFi}} 0.27 ; 95 \% \mathrm{CI}\right.$ $0.08-0.88 ; P=0.03)$. The prognostic effect of high TILs was also observed in the multivariable analysis, except for patients with TNBC (Table 2). Presence of LVI was associated with a worse prognosis in patients in the control arm in the univariable analysis $\left(\mathrm{HR}_{\mathrm{BCFi}} 1.49 ; 95 \% \mathrm{CI}\right.$ $1.08-2.05 ; P=0.02)$, and the results were essentially the same in multivariable analysis $\left(\mathrm{HR}_{\mathrm{BCFi}} 1.39 ; 95 \% \mathrm{CI}\right.$ 0.99-1.95; $P=0.06$ ) (Table 2).

\section{TILs as a predictive marker for TAM benefit in the ER+ subgroup}

The predictive value of TILs for TAM treatment was evaluated in the ER+ cohort $(n=321)$. In our previous follow-up study, TAM prolonged BCFi in the study population with ER+ tumours $(n=362)\left(\mathrm{HR}_{\mathrm{BCFi}} 0.62\right.$; 95\% CI $0.47-0.82 ; P=0.001$ ) [18], and this was also true in the present study cohort $(n=321)\left(\mathrm{HR}_{\mathrm{BCFi}} 0.65 ; 95 \%\right.$ CI $0.49-0.86 ; P=0.002)$. The proportions of tumours with low, intermediate and high TILs were 63\% ( $n=$ $107 / 171), 29 \%(n=50 / 171)$ and $8 \%(n=14 / 171)$ in the control group and 64\% $(n=96 / 150), 29 \%(n=44 / 150)$ and $7 \%(n=10 / 150)$ in the TAM group, respectively. Figure $5 \mathrm{a}-\mathrm{c}$ illustrates the outcome $(\mathrm{BCFi})$ stratified by TIL categories and treatment allocation. In the univariable analysis, TAM improved the outcome for patients with low $\left(\mathrm{HR}_{\mathrm{BCFi}} 0.66 ; 95 \%\right.$ CI $0.46-0.93$; $P=0.02)$ and intermediate TILs $\left(\mathrm{HR}_{\mathrm{BCFi}} 0.59 ; 95 \% \mathrm{CI}\right.$ $0.35-1.00, P=0.05)$. In contrast, the outcome of patients with high TILs was not affected by adjuvant TAM $\left(\mathrm{HR}_{\mathrm{BCF}}\right.$ 0.89 ; 95\% CI 0.26-3.07; $P=0.86$ ). There was no clear association between OS and TIL categories as illustrated in Fig. 6a-c.

Furthermore, the differential effect of TAM treatment on BCFi in TIL subgroups was analysed in a Cox model including TAM treatment and TILs and an interaction term. The TIL variable was divided into two categories at an exploratory 50\% cut-off (non-LPBC as $<50 \%$ vs. LPBC as $\geq 50 \%$ ), based on the above predictive results. Among the ER+ samples, 93\% $(n=297 / 321)$ were categorised as non-LPBC and $7 \%(n=24 / 321)$ as LPBC. The effect of TAM was stronger in patients with non-LPBC $\left(\mathrm{HR}_{\mathrm{BCFi}} 0.63 ; 95 \% \mathrm{CI} 0.47-0.84 ; P=0.002\right)$ than in patients with $\mathrm{LPBC}\left(\mathrm{HR}_{\mathrm{BCFi}} 0.84 ; 95 \% \mathrm{CI} 0.24-2.86 ; P=\right.$ 0.77 ), but the evidence for an interaction between TAM treatment and level of TIL infiltration on BCFi was weak $\left(P_{\text {interaction }}=0.65\right)($ Table 3$)$. 
Table 1 Distribution of TILs according to patient and tumour characteristics ( $n=477)$

\begin{tabular}{|c|c|c|c|c|}
\hline Variable & $\begin{array}{l}\text { TIL low }(<10 \%) \\
n(\%)\end{array}$ & $\begin{array}{l}\text { TIL intermediate (10-49\%) } \\
n(\%)\end{array}$ & $\begin{array}{l}\text { TIL high ( } \geq 50 \%) \\
n(\%)\end{array}$ & $P$ value $^{a}$ \\
\hline Age (years) & & & & 0.02 \\
\hline$<40$ & $41(44)$ & $32(34)$ & $21(22)$ & \\
\hline$\geq 40$ & $207(54)$ & $125(33)$ & $51(13)$ & \\
\hline Nodal status & & & & 0.34 \\
\hline 0 & $65(47)$ & $42(31)$ & $30(22)$ & \\
\hline $1-3$ & $137(59)$ & $66(28)$ & $30(13)$ & \\
\hline$\geq 4$ & $46(44)$ & $47(45)$ & $12(11)$ & \\
\hline Missing & 0 & 2 & 0 & \\
\hline Tumour size (mm) & & & & 0.06 \\
\hline$\leq 20$ & $97(57)$ & $52(31)$ & $20(12)$ & \\
\hline$>20$ & $151(49)$ & $104(34)$ & $52(17)$ & \\
\hline Missing & 0 & 1 & 0 & \\
\hline Histological grade (NHG) & & & & $<0.001$ \\
\hline 1 & $44(86)$ & $7(14)$ & 0 & \\
\hline 2 & $135(70)$ & $52(27)$ & $5(3)$ & \\
\hline 3 & $56(27)$ & $91(43)$ & $64(30)$ & \\
\hline Missing & 13 & 7 & 3 & \\
\hline ER & & & & $<0.001$ \\
\hline Negative & $45(29)$ & $63(40)$ & $48(31)$ & \\
\hline Positive & $203(63)$ & $94(29)$ & $24(8)$ & \\
\hline PR & & & & $<0.001$ \\
\hline Negative & $41(27)$ & $63(41)$ & $50(33)$ & \\
\hline Positive & $206(64)$ & $93(29)$ & $21(7)$ & \\
\hline Missing & 1 & 1 & 1 & \\
\hline HER2 & & & & 0.001 \\
\hline Negative & $205(56)$ & $109(30)$ & $50(14)$ & \\
\hline Positive & $22(33)$ & $28(42)$ & $16(24)$ & \\
\hline Missing & 21 & 20 & 6 & \\
\hline LVI & & & & 0.87 \\
\hline Absent & $140(54)$ & $76(30)$ & $42(16)$ & \\
\hline Present & $108(50)$ & $81(37)$ & $28(13)$ & \\
\hline Missing & 0 & 0 & 2 & \\
\hline Ki67 (\%) & & & & $<0.001$ \\
\hline$\leq 10$ & $126(71)$ & $40(23)$ & $12(7)$ & \\
\hline $11-25$ & $60(56)$ & $33(31)$ & $14(13)$ & \\
\hline$\geq 26$ & $22(20)$ & $53(48)$ & $36(32)$ & \\
\hline Missing & 40 & 31 & 10 & \\
\hline Histopathological type & & & & $<0.001$ \\
\hline Ductal/NST & $200(52)$ & $134(35)$ & $48(13)$ & \\
\hline Lobular & $29(81)$ & $7(19)$ & 0 & \\
\hline Medullary & 0 & $3(13)$ & $20(87)$ & \\
\hline Other & $9(75)$ & $2(17)$ & $1(8)$ & \\
\hline Missing & 10 & 11 & 3 & \\
\hline
\end{tabular}


Table 1 Distribution of TILs according to patient and tumour characteristics ( $n=477)$ (Continued)

\begin{tabular}{|c|c|c|c|c|}
\hline Variable & $\begin{array}{l}\text { TIL low }(<10 \%) \\
n(\%)\end{array}$ & $\begin{array}{l}\text { TIL intermediate (10-49\%) } \\
n(\%)\end{array}$ & $\begin{array}{l}\text { TIL high ( } \geq 50 \%) \\
n(\%)\end{array}$ & $P$ value $^{a}$ \\
\hline Subtype & & & & $<0.001$ \\
\hline $\mathrm{ER}+/ \mathrm{HER} 2-$ & $176(69)$ & $65(25)$ & $16(6)$ & \\
\hline HER2+ & $22(33)$ & $28(42)$ & $16(24)$ & \\
\hline TNBC & $20(21)$ & $42(44)$ & $33(35)$ & \\
\hline Missing & 30 & 22 & 7 & \\
\hline Total & $248(52)$ & 157 (33) & $72(15)$ & \\
\hline
\end{tabular}

${ }^{a}$ Chi2 test for trend, except for the non-ordinal variables histopathological type and subtype, when conventional chi2 test was used Abbreviations: ER oestrogen receptor, HER2 human epidermal growth factor receptor 2, LVI lymphovascular invasion, NST no special type, NHG Nottingham histological grade, $P R$ progesterone receptor, $T$ ILs tumour-infiltrating lymphocytes, TNBC triple-negative breast cancer

\section{Discussion}

In this study, we showed that high TILs is associated with a relative reduction of the incidence of invasive $\mathrm{BC}$ related events by $60 \%$ after approximately 30 years of follow-up. Interestingly, similar results were observed across BC subtypes including patients with ER+/HER2- tumours. Despite the association of high TILs with characteristics that typically indicate poor prognosis, the positive prognostic value of high TIL infiltration was retained in multivariable analysis, thereby emphasising TILs as an important independent long-term favourable prognostic factor. In addition, we present a possible

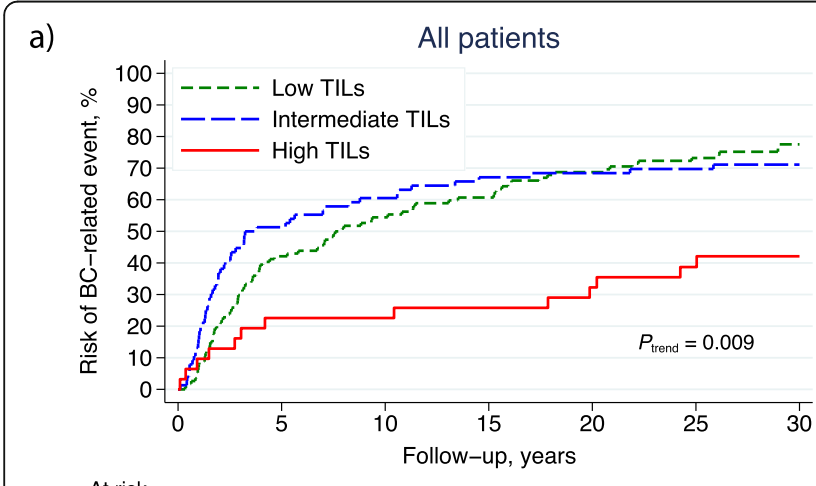

b)

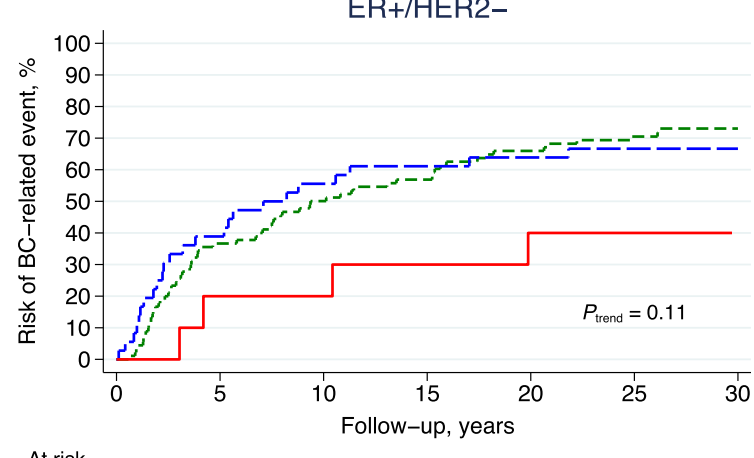

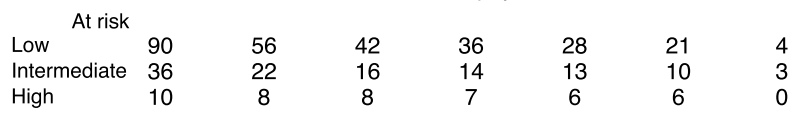

c)

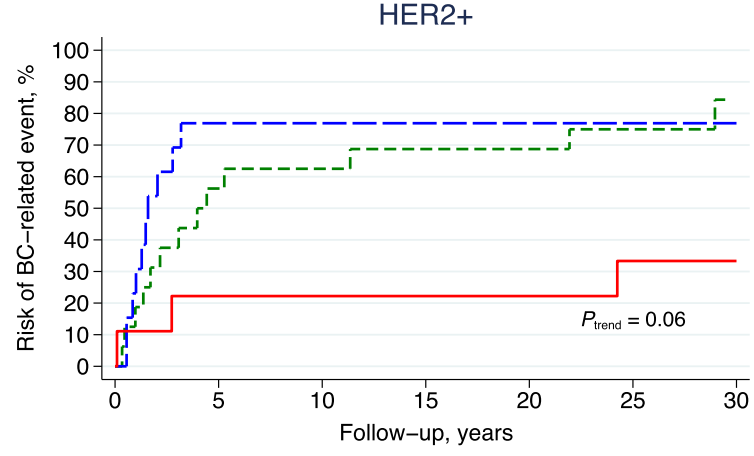

d)

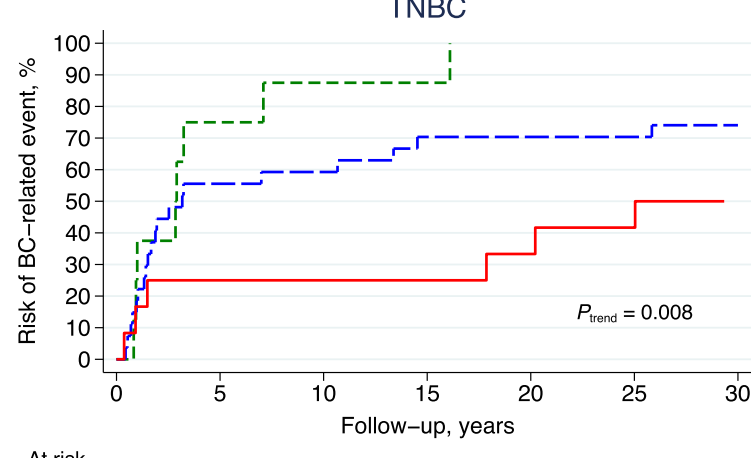

TNBC

$\begin{array}{lccccccc}\text { Low } & 16 & 6 & 5 & 4 & 4 & 3 & 0 \\ \text { Intermediate } & 13 & 3 & 3 & 3 & 3 & 3 & 1 \\ \text { High } & 9 & 7 & 7 & 7 & 7 & 5 & 1\end{array}$

\begin{tabular}{lccccccc}
\multicolumn{2}{c}{ At risk } & & & & & & \\
Low & 8 & 2 & 1 & 1 & 0 & 0 & 0 \\
Intermediate & 27 & 11 & 10 & 6 & 6 & 6 & 1 \\
High & 12 & 9 & 9 & 9 & 8 & 7 & 0
\end{tabular}

Fig. 3 a-d Cumulative incidence of breast cancer (BC)-related events (BCFi) in different breast cancer subtypes. The panel illustrates the result of different levels of TILs in a all patients, and patients with the following breast cancer subtypes; $\mathbf{b}$ ER+/HER2-; c HER2+; and $\mathbf{d}$ TNBC. The patients were allocated to no adjuvant systemic treatment and TILs were categorised as low: $<10 \%$, intermediate: $10-49 \%$ and high: $\geq 50 \%$. Abbreviations: BCFi breast cancer-free interval, ER oestrogen receptor, HER2 human epidermal growth factor receptor 2, TILs tumour-infiltrating lymphocytes, TNBC triple-negative breast cancer 

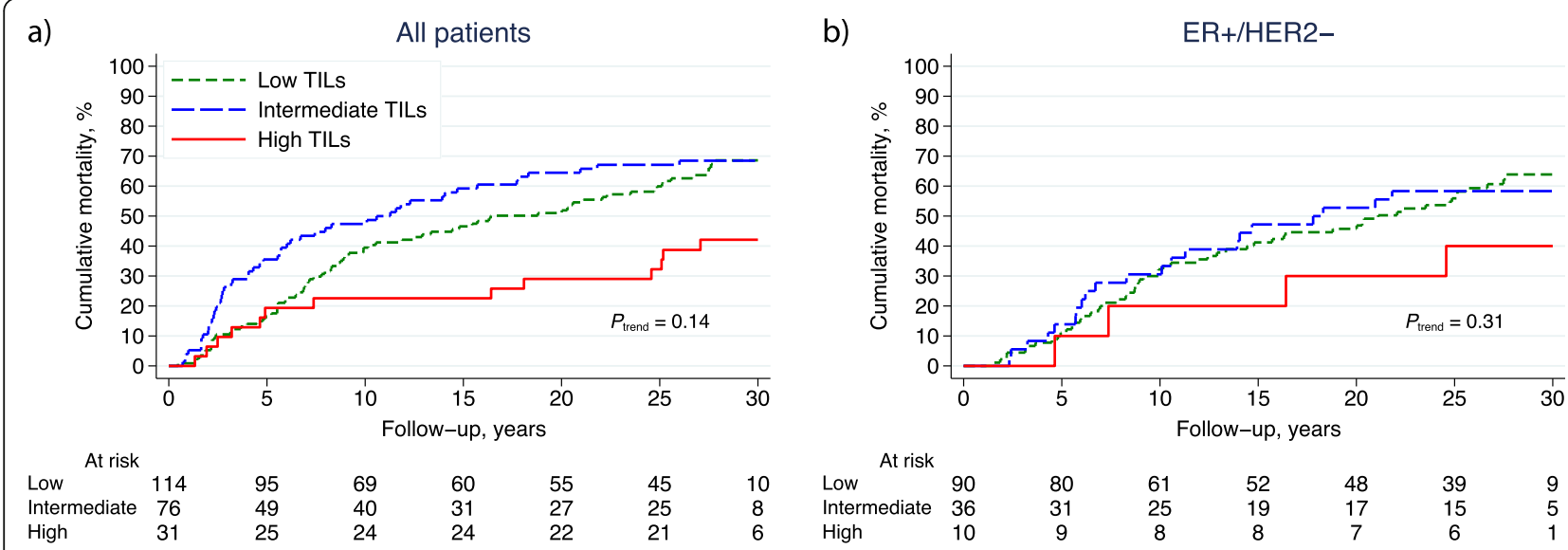

c)

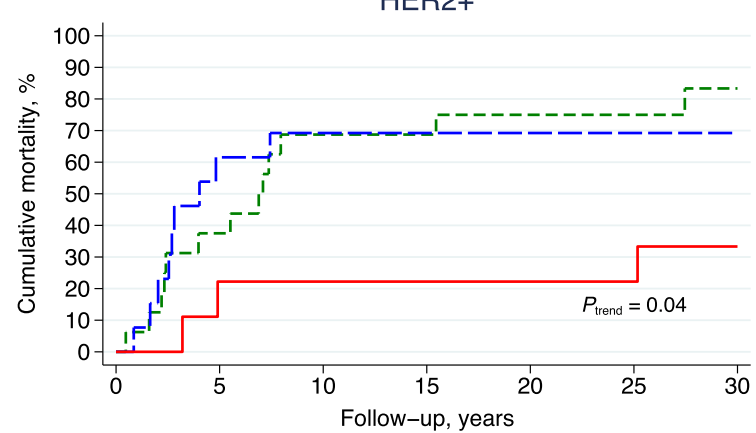

d)

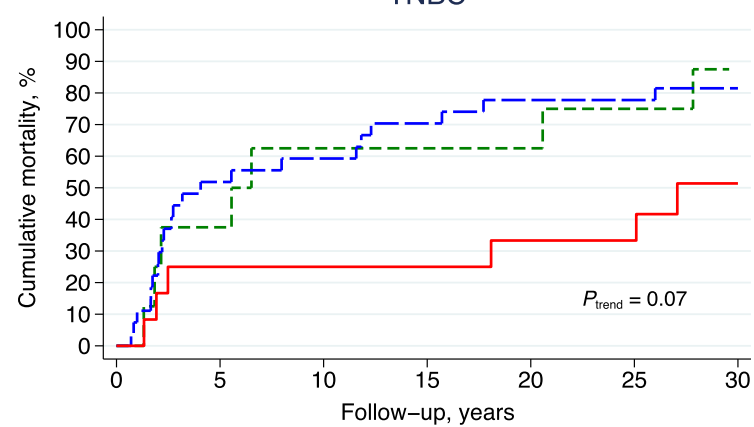

$\begin{array}{lllllll}\text { High } & 9 & 7 & 7 & 7 & 7 & 7\end{array}$

Fig. 4 a-d Cumulative mortality (OS) in different breast cancer subtypes. The panel illustrates the result of different levels of TILs in a all patients, and patients with the following breast cancer subtypes; b ER+/HER2-; c HER2+; and $\mathbf{d}$ TNBC. The patients were allocated to no adjuvant systemic treatment and TILs were categorised as low: < 10\%, intermediate: 10-49\% and high: $\geq 50 \%$. Abbreviations: ER oestrogen receptor, HER2 human epidermal growth factor receptor 2, OS overall survival, TILs tumour-infiltrating lymphocytes, TNBC triple-negative breast cancer

predictive value of TILs on TAM benefit in patients with ER+ tumours, indicating that high infiltration of TILs might be linked to endocrine-resistant tumours.

Our results on the prognostic association of TILs in TNBC and HER2+ subtypes are in line with previous results $[3,8,9,11]$. The associations of high TILs and negative hormone receptor status, higher NHG and higher Ki67 emphasise a higher immune infiltration in TNBC tumours. In the St. Gallen guidelines 2019, the panel recommended that TILs should be routinely characterised in TNBC tumours due to their prognostic value; however, there was not enough data on TILs to guide the use of neoadjuvant and adjuvant treatment [19]. Our data support the prognostic value of TILs in TNBC, and interestingly, our stratification of subtypes revealed similar results in patients with ER+/HER2- tumours. Previous prognostic study designs of TILs in ER+/HER2 - tumours are not consistent and often based on trials of adjuvant chemo-endocrine treatment as well as neoadjuvant studies [3, 6, 7]. In a meta-analysis by
Denkert et al. that included six neoadjuvant chemotherapy studies with pre-and postmenopausal women, patients with ER+/HER2 - tumours and low level of TILs had an improved OS after 10 years, also after adjusting for pCR [6]. Our results show an association of high immune infiltration and better prognosis in the ER+/HER2 - subgroup, which has not been reported in other adjuvant studies assessing TILs [3, 7, 11].

Previous studies of the predictive value of TILs in ER+ tumours mainly included chemotherapy trials and showed no predictive effect on either anthracycline therapy or additional taxane treatment $[3,11]$. In the present study, we observed a TAM benefit regarding BCFi in patients with ER+ tumours and non-LPBC tumours (TILs $<50 \%$ ), while no effect was shown in patients with LPBC tumours (TILs $\geq 50 \%$ ). However, this study was not powered to detect any interaction effect between TILs and TAM, and hence, we could not demonstrate any treatment interaction. A few studies have reported findings in contrast with our results. In a study of 563 
Table 2 Cox regression analyses of BCFi and OS in patients randomised to no adjuvant medical treatment

\begin{tabular}{|c|c|c|c|c|}
\hline \multirow{3}{*}{ Variable } & \multicolumn{2}{|c|}{ Univariable } & \multicolumn{2}{|c|}{ Multivariable $^{\mathrm{a}}$} \\
\hline & $\overline{\mathrm{BCFi}}$ & OS & $\overline{\mathrm{BCFi}}$ & OS \\
\hline & \multicolumn{4}{|c|}{ HR $(95 \% \mathrm{Cl}) ; P$ value } \\
\hline \multicolumn{5}{|l|}{ TILs, category ${ }^{b}$} \\
\hline All subtypes & \multicolumn{2}{|c|}{$(n=221)$} & \multicolumn{2}{|c|}{$(n=213)$} \\
\hline Low (Ref.) & 1.00 & 1.00 & 1.00 & 1.00 \\
\hline Intermediate & $1.10(0.78-1.54) ; 0.61$ & $1.26(0.88-1.80) ; 0.21$ & $0.61(0.40-0.93) ; 0.02^{c}$ & $0.65(0.41-1.02) ; 0.06$ \\
\hline High & $0.40(0.22-0.71) ; 0.002$ & $0.52(0.29-0.95) ; 0.03$ & $0.22(0.11-0.43) ;<0.001$ & $0.23(0.11-0.48) ;<0.001$ \\
\hline ER+/HER2- & \multicolumn{2}{|c|}{$(n=136)$} & \multicolumn{2}{|c|}{$(n=135)$} \\
\hline Low (Ref.) & 1.00 & 1.00 & 1.00 & 1.00 \\
\hline Intermediate & $1.02(0.63-1.64) ; 0.94$ & $1.02(0.61-1.71) ; 0.95$ & $0.69(0.42-1.15) ; 0.16$ & $0.65(0.37-1.15) ; 0.14$ \\
\hline High & $0.40(0.14-1.09) ; 0.07$ & $0.55(0.20-1.52) ; 0.25$ & $0.20(0.06-0.60) ; 0.004$ & $0.30(0.10-0.96) ; 0.04$ \\
\hline HER2+ & \multicolumn{2}{|c|}{$(n=38)$} & \multicolumn{2}{|c|}{$(n=35)$} \\
\hline Low (Ref.) & 1.00 & 1.00 & 1.00 & 1.00 \\
\hline Intermediate & $1.47(0.62-3.49) ; 0.39$ & $1.07(0.45-2.56) ; 0.88$ & $0.47(0.14-1.60) ; 0.23$ & $0.38(0.11-1.31) ; 0.13$ \\
\hline High & $0.28(0.08-0.97) ; 0.05$ & $0.27(0.08-0.96) ; 0.04$ & $0.06(0.01-0.56) ; 0.01$ & 0.05 (0.01-0.39); 0.005 \\
\hline TNBC & \multicolumn{2}{|c|}{$(n=47)$} & \multicolumn{2}{|c|}{$(n=43)$} \\
\hline Low (Ref.) & 1.00 & 1.00 & 1.00 & 1.00 \\
\hline Intermediate & $0.76(0.31-1.87) ; 0.55$ & $1.24(0.49-3.14) ; 0.65$ & $0.59(0.21-1.67) ; 0.32$ & $1.02(0.34-3.11) ; 0.97$ \\
\hline High & $0.27(0.08-0.88) ; 0.03$ & $0.44(0.14-1.36) ; 0.16$ & $0.38(0.11-1.39) ; 0.15$ & $0.59(0.16-2.26) ; 0.44$ \\
\hline Covariables & \multicolumn{2}{|c|}{$(n=216-221)$} & \multicolumn{2}{|c|}{$(n=213)$} \\
\hline \multicolumn{5}{|l|}{ Age (years) } \\
\hline$<40$ (Ref.) & 1.00 & 1.00 & 1.00 & 1.00 \\
\hline$\geq 40$ & $0.72(0.49-1.04) ; 0.08$ & $0.65(0.44-0.96) ; 0.03$ & $0.60(0.40-0.89) ; 0.01$ & $0.56(0.37-0.85) ; 0.006$ \\
\hline \multicolumn{5}{|l|}{ Nodal status } \\
\hline 0 (Ref.) & 1.00 & 1.00 & 1.00 & 1.00 \\
\hline $1-3$ & $1.31(0.87-1.96) ; 0.19$ & $1.59(1.03-2.47) ; 0.04$ & $1.21(0.77-1.91) ; 0.40$ & 1.69 (1.03-2.77); 0.04 \\
\hline$\geq 4$ & $2.33(1.49-3.64)_{i}<0.001$ & $2.81(1.75-4.52) ;<0.001$ & $2.03(1.25-3.29) ; 0.004$ & $2.70(1.58-4.52) ;<0.001$ \\
\hline \multicolumn{5}{|c|}{ Tumour size (mm) } \\
\hline$\leq 20$ (Ref.) & 1.00 & 1.00 & 1.00 & 1.00 \\
\hline$>20$ & $1.04(0.75-1.45) ; 0.80$ & $0.92(0.66-1.29) ; 0.63$ & $1.23(0.86-1.76) ; 0.25$ & $1.04(0.72-1.51) ; 0.84$ \\
\hline \multicolumn{5}{|c|}{ Histological grade (NHG) } \\
\hline 1 (Ref.) & 1.00 & 1.00 & 1.00 & 1.00 \\
\hline 2 & $1.51(0.84-2.72) ; 0.17$ & $1.34(0.73-2.45) ; 0.35$ & $1.36(0.74-2.48) ; 0.32$ & $1.13(0.60-2.11) ; 0.71$ \\
\hline 3 & $1.82(1.03-3.23) ; 0.04$ & $1.96(1.09-3.54) ; 0.03$ & $2.70(1.36-5.33) ; 0.004$ & $2.25(1.08-4.66) ; 0.03$ \\
\hline \multicolumn{5}{|l|}{ ER } \\
\hline Negative (Ref.) & 1.00 & 1.00 & 1.00 & 1.00 \\
\hline Positive & $0.94(0.66-1.34) ; 0.74$ & 0.69 (0.49-0.99); 0.04 & $0.41(0.12-1.36) ; 0.15$ & $0.37(0.11-1.27) ; 0.11$ \\
\hline \multicolumn{5}{|l|}{ PR } \\
\hline Negative (Ref.) & 1.00 & 1.00 & 1.00 & 1.00 \\
\hline Positive & $1.06(0.75-1.49) ; 0.75$ & $0.80(0.57-1.14) ; 0.21$ & $2.38(0.77-7.30) ; 0.13$ & $1.76(0.57-5.48) ; 0.33$ \\
\hline \multicolumn{5}{|l|}{ HER2 } \\
\hline Negative (Ref.) & 1.00 & 1.00 & 1.00 & 1.00 \\
\hline Positive & $1.10(0.72-1.69) ; 0.65$ & $1.26(0.81-1.94) ; 0.30$ & $1.05(0.66-1.67) ; 0.85$ & $1.11(0.68-1.82) ; 0.67$ \\
\hline
\end{tabular}


Table 2 Cox regression analyses of BCFi and OS in patients randomised to no adjuvant medical treatment (Continued)

\begin{tabular}{|c|c|c|c|c|}
\hline \multirow[b]{2}{*}{ Variable } & \multicolumn{2}{|c|}{ Univariable } & \multicolumn{2}{|c|}{ Multivariable $^{a}$} \\
\hline & $\mathrm{BCFi}$ & os & $\mathrm{BCFi}$ & OS \\
\hline & \multicolumn{4}{|c|}{ HR $(95 \% \mathrm{Cl}) ; P$ value } \\
\hline \multicolumn{5}{|l|}{ LVI } \\
\hline Absent (Ref.) & 1.00 & 1.00 & 1.00 & 1.00 \\
\hline Present & $1.49(1.08-2.05) ; 0.02$ & $1.26(0.90-1.76) ; 0.18$ & $1.39(0.99-1.95) ; 0.06$ & $1.05(0.73-1.51) ; 0.78$ \\
\hline
\end{tabular}

All analyses were stratified by study region

Abbreviations: $B C F i$ breast cancer free-interval, $C l$ confidence interval, ER oestrogen receptor, $H E R 2$ human epidermal growth factor receptor $2, H R$ hazard ratio, $L V I$ lymphovascular invasion, NHG Nottingham histological grade, OS overall survival, PR progesterone receptor, TILs tumour-infiltrating lymphocytes, TNBC triplenegative breast cancer

${ }^{a}$ The following variables were included in multivariable analysis: age ( $\geq 40$ vs. $<40$ years), nodal status $(0$ vs.1-3 vs. $\geq 4)$, tumour size ( $>20$ mm vs. $\leq 20$ mm), histological grade (1 vs. 2 vs. 3), ER (positive vs. negative), PR (positive vs. negative), HER2 (positive vs. negative), LVI (present vs. absent) and TILs (high vs. intermediate vs. low)

${ }^{\mathrm{b}}$ TILs were categorised as low: $<10 \%$, intermediate: $10-49 \%$ and high: $\geq 50 \%$

${ }^{\mathrm{C}} \mathrm{A}$ series of multivariable analyses including TILs and only one additional prognostic variable at a time revealed that the univariable effect of intermediate vs. low TILs on outcome was mainly confounded by NHG. In the prognostic cohort, $65 \%$ of the patients with intermediate TILs had NHG 3 tumours

postmenopausal patients randomised to TAM or no adjuvant therapy, patients with low levels of CD8+ TILs did not seem to have any TAM benefit [28]. Dietci et al. found a higher, but not significant, Ki67 suppression after neoadjuvant endocrine therapy in the high $(\geq 10 \%)$
TIL subgroup [15]. This indicated a better effect of endocrine therapy in these trials for patients with abundance of immune infiltration.

In this study, high TILs were associated with better prognosis and also co-variables indicating worse

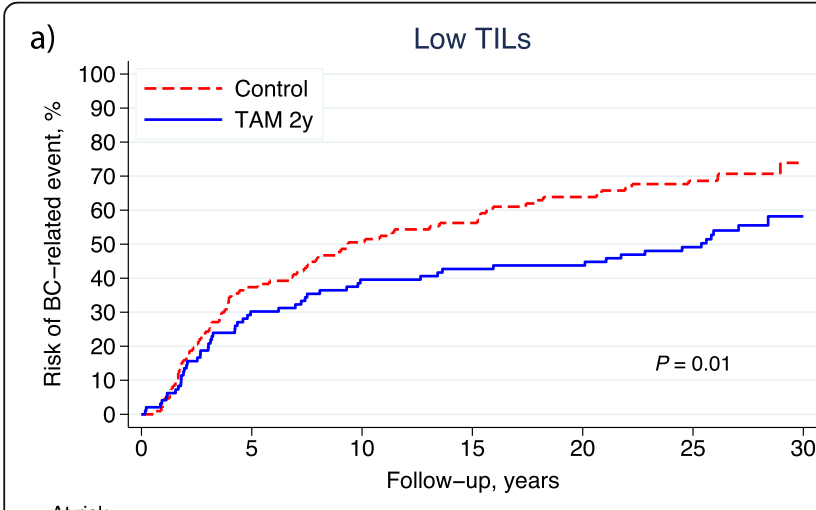

b) Intermediate TILs

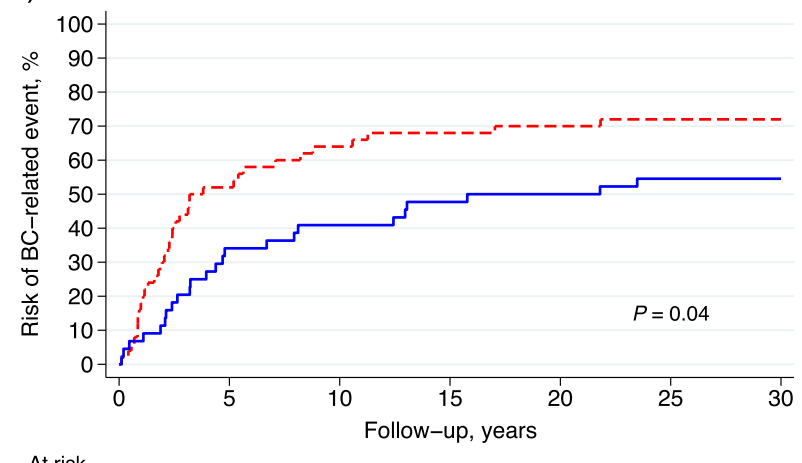

At risk

Control 50

TAM 2 y 44

$\begin{array}{llllllll}\text { At risk } & & & & & \\ \text { Control } & 107 & 65 & 49 & 43 & 35 & 26 & 4 \\ \text { TAM 2y } & 96 & 67 & 57 & 53 & 50 & 39 & 2\end{array}$

C)

c) High TILs

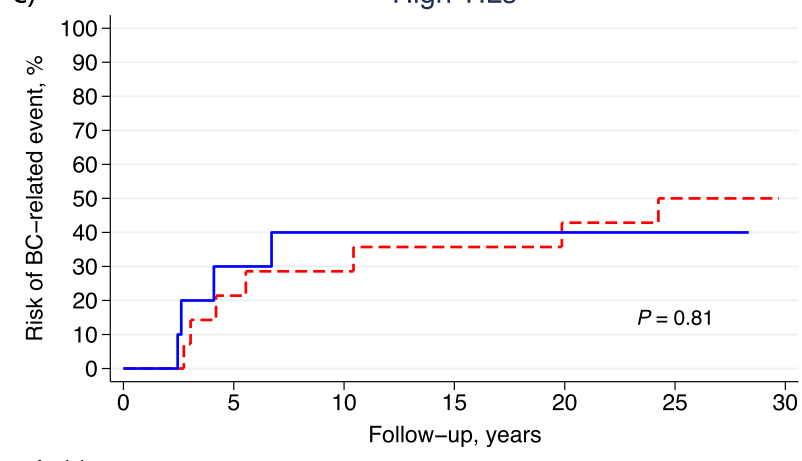

$\begin{array}{lccccccc}\text { At risk } & & & & & & & \\ \text { Control } & 14 & 11 & 10 & 9 & 7 & 6 & 0 \\ \text { TAM 2y } & 10 & 7 & 6 & 6 & 6 & 5 & 0\end{array}$

Fig. 5 a-c Cumulative incidence of breast cancer (BC)-related events (BCFi) stratified by treatment allocation (control vs. TAM) for patients whose tumours were ER-positive and had a low TILs (<10\%); b intermediate TILs (10-49\%) and c high TILs ( $\geq 50 \%)$. Abbreviations: BCFi breast cancer-free interval, ER oestrogen receptor, TAM tamoxifen, TILs tumour-infiltrating lymphocytes 


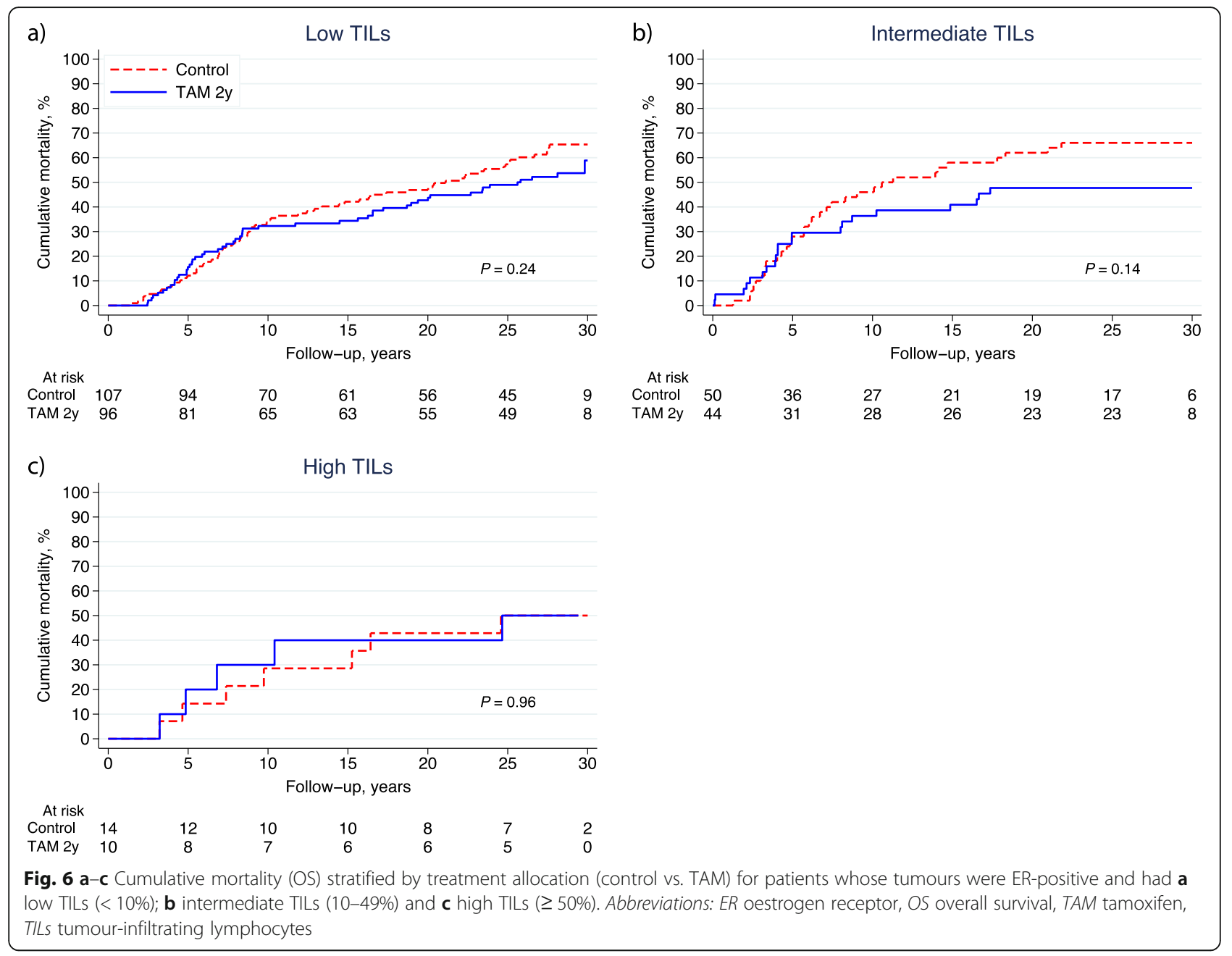

prognosis (high NHG, negative hormone receptor status, high proliferation). These findings highlight LPBC as an independent favourable prognostic factor. Importantly, LPBC was also of long-term prognostic relevance even after three decades of follow-up. The selection of study participants, shorter follow-up and the low proportion of LPBC in ER+/HER2- tumours are putative explanations to the divergent study results in this particular subtype.
The distribution of subsets of the immune cell population, such as $\mathrm{CD} 8+$, $\mathrm{T}$ regulatory cells and macrophages, could be an additional explanatory factor that was not addressed in our study. The favourable outcome for patients with ER+/LPBC tumours did not seem to be further improved by TAM treatment. The relation of immune infiltration and tumour mutational burden is thought to be associated with breast cancer

Table 3 Predictive value of TILs for TAM response with respect to breast cancer-free interval (ER-positive cohort)

\begin{tabular}{|c|c|c|c|c|}
\hline \multirow[b]{2}{*}{ Variable } & \multicolumn{2}{|c|}{ Univariable $(n=321)$} & \multicolumn{2}{|c|}{ Multivariable $^{a}(n=277)$} \\
\hline & HR (95\% Cl) & $P$ value & HR $(95 \% \mathrm{Cl})$ & $P$ value \\
\hline TAM vs. control in TILs <50\% & $0.63(0.47-0.84)$ & 0.002 & $0.60(0.43-0.83)$ & 0.002 \\
\hline TAM vs. control in TILs $\geq 50 \%$ & $0.84(0.24-2.86)$ & 0.77 & $0.90(0.22-3.64)$ & 0.88 \\
\hline Interaction TILs × TAM (HR ratio) & $0.75(0.21-2.65)$ & 0.65 & $0.67(0.16-2.83)$ & 0.59 \\
\hline
\end{tabular}

Separate effects of tamoxifen in the two TIL groups were estimated by changing the reference group for TILs in the Cox model with main effects for treatment and TILs and an interaction effect. The HR for interaction (0.75) is the ratio between the tamoxifen effects in low and high TILs, i.e. 0.63/0.84. All analyses were stratified by study region

Abbreviations: $E R$ oestrogen receptor, Cl confidence interval, HR hazard ratio, TAM tamoxifen, TILs tumour-infiltrating lymphocytes

${ }^{a}$ The following variables were included in the multivariable analysis: age ( $\geq 40$ vs. $<40$ years), nodal status ( 0 vs.1 -3 vs. $\left.\geq 4\right)$, tumour size $(>20 \mathrm{~mm}$ vs. $\leq 20 \mathrm{~mm}$ ), histological grade (1 vs. 2 vs. 3), ER (positive vs. negative), PR (positive vs. negative), HER2 (positive vs. negative) and LVI (present vs. absent) 
outcomes [29], and one hypothesis is that the tumour mutational load explains a possible endocrine resistance noted in the high TIL subgroup.

The strengths of this study are that it was based on a randomised controlled trial and included only premenopausal patients with almost 30 years of follow-up data. The results are important both due to the long-term risk of BC-related events for patients with ER+/HER2- tumours [17] and for the younger patient category. Moreover, the treatment arm consisted of only 2 years of adjuvant TAM and the patients in the control arm received no systemic therapy. Despite it has been more than three decades since the start of the SBII:2pre trial, TAM is still the adjuvant endocrine drug of choice for most premenopausal women and our data are therefore of interest for contemporary patients. The scoring of general TILs was performed by a BC pathologist on whole tumour sections, rather than tissue microarrays, according to published standard methodology [5].

The study limitations include the sample size of subgroup analyses, especially in the prognostic analyses of ER+/HER2-/LPBC tumours. TIL category was not evaluated as a continuous variable, nor did we determine TIL phenotype classifications. However, the application of TILs as a categorised variable is in line with other studies [6]. The cut-off (50\%) in the interaction analysis was based upon a visual determination from the predictive cumulative incidence curves, and the cut-off level could thus be considered data-driven. The focus of this study was on the ER+/HER2- subgroup, and because of the incomplete estimations of Ki67 and PR, we were not able to distinguish between Luminal A and B-like tumours.

According to current guidelines, many patients included in the present cohort would today be treated with chemoendocrine therapy and some patients would also be offered a gonadotropin-releasing hormone analogue [19, 20]. The possibility to de-escalate chemotherapy treatment by gene expression analyses is currently recommended as an option for some women [30,31]. Our data, indicating prolonged $\mathrm{BC}$-specific survival for patients with $\mathrm{ER}+$ / HER2- and LPBC tumours, might aid in identifying patients with excellent long-term prognosis for which reduced use of adjuvant chemotherapy could be considered. TILs as a predictive marker for endocrine benefit for premenopausal patients would also be desirable, and the association of TILs and outcomes may furthermore be dependent on the endocrine treatment option [32]. However, larger studies are warranted to examine the predictive effect of TILs for TAM efficacy as well as for other drugs including immunotherapy in this particular subgroup of patients. Moreover, the genomic analysis of primary tumour tissue including mutational load from the SBII:2pre cohort, in relation to TILs and outcomes, is an interesting future research topic.

\section{Conclusions}

High immune cell infiltration was independently associated with prolonged BCFi in premenopausal patients allocated to no systemic therapy in a randomised trial. The finding was extended to comprise all $\mathrm{BC}$ subtypes after nearly three decades of follow-up. Furthermore, adjuvant TAM was beneficial in patients with $\mathrm{ER}+/$ non-LPBC tumours, but the predictive effect of TILs could not be confirmed.

\section{Supplementary Information}

The online version contains supplementary material available at https://doi. org/10.1186/s13058-020-01364-w.

Additional file 1. Patient and tumour characteristics of study cohort $(n=477)$ and for the excluded patients with no scored TILs $(n=60)$.

\section{Abbreviations}

BC: Breast cancer; BCFi: Breast cancer-free interval; Cl: Confidence interval; DCIS: Ductal carcinoma in situ; ER: Oestrogen receptor; HER2: Human epidermal growth factor receptor 2; HR: Hazard ratio;

IHC: Immunohistochemistry; ISH: In situ hybridization; LVI: Lymphovascular invasion; LPBC: Lymphocyte-predominant breast cancer; NHG: Nottingham histological grade; OS: Overall survival; pCR: Pathological complete response; PR: Progesterone receptor; TAM: Tamoxifen; TILs: Tumour-infiltrating lymphocytes; TNBC: Triple-negative breast cancer; UICC: Union for International Cancer Control

\section{Acknowledgements}

The authors thank all patients who participated in the original SBIl:2pre trial collaborators at the participating hospitals and the Department of Oncology, Region Jönköping County, for making this study possible.

\section{Authors' contributions}

$\mathrm{CL}$ designed the study, performed the statistical analyses and database construction, analysed data and drafted the manuscript. POB designed the study, performed the statistical analyses, interpreted data and critically revised the manuscript. ME had previously assembled follow-up data, interpreted data and critically revised the manuscript. MF interpreted data and critically revised the manuscript. CF prepared tissue samples, interpreted data and critically revised the manuscript. BN and OS interpreted data and critically revised the manuscript. UK assessed the histological examination of tissue samples, provided microscopic pictures and critically revised the manuscript. LR was responsible for study conception and design, interpreted data and critically revised the manuscript. The authors read and approved the final manuscript.

\section{Funding}

This study was funded by grants from The Swedish Breast Cancer Association, The Swedish Breast Cancer Group, The Swedish Cancer Society, The Mrs. Berta Kamprad Foundation, The Anna and Edwin Berger's Foundation, The Gustav V Jubilee Fund, Governmental Funding of Clinical Research within the Swedish National Health Service and Futurum - the Academy for Health and Care, Region Jönköping County. Open Access funding provided by Lund University.

\section{Availability of data and materials}

The datasets generated and/or analysed during the current study are available from the corresponding author on reasonable request.

\section{Ethics approval and consent to participate}

The SBIl:2pre study was previously approved by both the ethical committees in Lund and Linköping, Sweden, and informed consent was obtained from all participants included in this study. The follow-up study has an ethical approval by the ethical committee of Lund (Dnr LU 2015/350). For the purpose of this study, there is an additional complementary approved application (Dnr LU 2017/97). Approval from the Biobank Sweden was achieved. This article does not contain any studies with animal data. 


\section{Consent for publication}

Not applicable.

\section{Competing interests}

Author Maria Ekholm has had a consultant/advisory role in Pfizer and Novartis. Ute Krüger has ownership in proHISTO. None of the authors has any competing interests, financial and non-financial, in relation to the work described.

\section{Author details}

'Department of Oncology, Region Jönköping County, Jönköping, Sweden. ${ }^{2}$ Department of Clinical Sciences Lund, Division of Oncology, Lund University, Lund, Sweden. ${ }^{3}$ Department of Biomedical and Clinical Sciences, Linköping University, Linköping, Sweden. ${ }^{4}$ Department of Clinical Sciences Lund, Division of Surgery, Lund University, Lund, Sweden. ${ }^{5}$ Department of Surgery, Skåne University Hospital, Malmö, Sweden.

\section{Received: 11 September 2020 Accepted: 30 October 2020}

Published online: 23 December 2020

\section{References}

1. Sorlie T, Perou CM, Tibshirani R, Aas T, Geisler S, Johnsen H, et al. Gene expression patterns of breast carcinomas distinguish tumor subclasses with clinical implications. Proc Natl Acad Sci U S A. 2001;98(19):10869-74.

2. Curigliano G, Burstein HJ, Winer EP, Gnant M, Dubsky P, Loibl S, et al. Deescalating and escalating treatments for early-stage breast cancer: the St. Gallen International Expert Consensus Conference on the Primary Therapy of Early Breast Cancer. Ann Oncol. 2017;28(8):1700-12.

3. Loi S, Sirtaine N, Piette F, Salgado R, Viale G, Van Eenoo F, et al. Prognostic and predictive value of tumor-infiltrating lymphocytes in a phase III randomized adjuvant breast cancer trial in node-positive breast cancer comparing the addition of docetaxel to doxorubicin with doxorubicinbased chemotherapy: BIG 02-98. J Clin Oncol. 2013;31(7):860-7.

4. Haricharan S, Bainbridge MN, Scheet P, Brown PH. Somatic mutation load of estrogen receptor-positive breast tumors predicts overall survival: an analysis of genome sequence data. Breast Cancer Res Treat. 2014;146(1): 211-20.

5. International Immuno-Oncology Biomarker Working Group on Breast Cancer. Everything you need to know about TILs in cancer. 2019. https:// www.tilsinbreastcancer.org/. Accessed 12 July 2020.

6. Denkert C, von Minckwitz G, Darb-Esfahani S, Lederer B, Heppner BI, Weber $\mathrm{KE}$, et al. Tumour-infiltrating lymphocytes and prognosis in different subtypes of breast cancer: a pooled analysis of 3771 patients treated with neoadjuvant therapy. Lancet Oncol. 2018;19(1):40-50.

7. Loi S, Michiels S, Salgado R, Sirtaine N, Jose V, Fumagalli D, et al. Tumor infiltrating lymphocytes are prognostic in triple negative breast cancer and predictive for trastuzumab benefit in early breast cancer: results from the FinHER trial. Ann Oncol. 2014;25(8):1544-50.

8. Adams S, Gray RJ, Demaria S, Goldstein L, Perez EA, Shulman LN, et al. Prognostic value of tumor-infiltrating lymphocytes in triple-negative breast cancers from two phase III randomized adjuvant breast cancer trials: ECOG 2197 and ECOG 1199. Clin Oncol. 2014;32(27):2959-66.

9. Carbognin L, Pilotto S, Nortilli R, Brunelli M, Nottegar A, Sperduti I, et al. Predictive and prognostic role of tumor-infiltrating lymphocytes for early breast cancer according to disease subtypes: sensitivity analysis of randomized trials in adjuvant and neoadjuvant setting. Oncologist. 2016; 21(3):283-91.

10. Denkert C, von Minckwitz G, Brase JC, Sinn BV, Gade S, Kronenwett R, et al. Tumor-infiltrating lymphocytes and response to neoadjuvant chemotherapy with or without carboplatin in human epidermal growth factor receptor 2positive and triple-negative primary breast cancers. J Clin Oncol. 2014;33(9): 983-91.

11. Dieci MV, Mathieu MC, Guarneri V, Conte P, Delaloge S, Andre F, et al. Prognostic and predictive value of tumor-infiltrating lymphocytes in two phase III randomized adjuvant breast cancer trials. Ann Oncol. 2015;26(8): 1698-704.

12. Ochi T, Bianchini G, Ando M, Nozaki F, Kobayashi D, Criscitiello C, et al. Predictive and prognostic value of stromal tumour-infiltrating lymphocytes before and after neoadjuvant therapy in triple negative and HER2-positive breast cancer. Eur J Cancer. 2019;118:41-8.
13. Issa-Nummer Y, Darb-Esfahani S, Loibl S, Kunz G, Nekljudova V, Schrader I, et al. Prospective validation of immunological infiltrate for prediction of response to neoadjuvant chemotherapy in HER2-negative breast cancer-a substudy of the neoadjuvant GeparQuinto trial. PLoS One. 2013;8(12): e79775.

14. Dunbier AK, Ghazoui Z, Anderson H, Salter J, Nerurkar A, Osin P, et al. Molecular profiling of aromatase inhibitor-treated postmenopausal breast tumors identifies immune-related correlates of resistance. Clin Cancer Res. 2013;19(10):2775.

15. Dieci MV, Frassoldati A, Generali D, Bisagni G, Piacentini F, Cavanna L, et al Tumor-infiltrating lymphocytes and molecular response after neoadjuvant therapy for HR+/HER2- breast cancer: results from two prospective trials. Breast Cancer Res Treat. 2017;163(2):295-302.

16. Early Breast Cancer Trialists' Collaborative Group (EBCTCG). Relevance of breast cancer hormone receptors and other factors to the efficacy of adjuvant tamoxifen: patient-level meta-analysis of randomised trials. Lancet. 2011;378(9793):771-84.

17. Pan H, Gray R, Braybrooke J, Davies C, Taylor C, McGale P, et al. 20-year risks of breast-cancer recurrence after stopping endocrine therapy at 5 years. $\mathrm{N}$ Engl J Med. 2017;377(19):1836-46.

18. Ekholm M, Bendahl PO, Ferno M, Nordenskjold B, Stal O, Ryden L. Effects of adjuvant tamoxifen over three decades on breast cancer-free and distant recurrence-free interval among premenopausal women with oestrogen receptor-positive breast cancer randomised in the Swedish SBII:2pre trial. Eur J Cancer. 2019;110:53-61.

19. Burstein HJ, Curigliano G, Loibl S, Dubsky P, Gnant M, Poortmans P, et al. Estimating the benefits of therapy for early-stage breast cancer: the St. Gallen International Consensus Guidelines for the primary therapy of early breast cancer 2019. Ann Oncol. 2019;30(10):1541-57.

20. Cardoso F, Kyriakides S, Ohno S, Penault-Llorca F, Poortmans P, Rubio IT, et al. Early breast cancer: ESMO Clinical Practice Guidelines for diagnosis, treatment and follow-up. Ann Oncol. 2019;30(10):1674.

21. Rydén $L$, Jönsson PE, Chebil G, Dufmats $M$, Fernö $M$, Jirström $K$, et al. Two years of adjuvant tamoxifen in premenopausal patients with breast cancer: a randomised, controlled trial with long-term follow-up. Eur J Cancer. 2005; 41(2):256-64.

22. Ekholm M, Bendahl PO, Fernö M, Nordenskjöld B, Stål O, Rydén L. Two years of adjuvant tamoxifen provides a survival benefit compared with no systemic treatment in premenopausal patients with primary breast cancer: long-term follow-up (> 25 years) of the phase III SBII: 2pre trial. J Clin Oncol. 2016;34(19):2232-8.

23. Svensk förening för Patologi. Bröstpatologi. Kvalitetsdokument för patologi. 2018. http://www.svfp.se/brostpatologi. . Accessed 10 Jan 2020.

24. Jirstrom K, Ryden L, Anagnostaki L, Nordenskjold B, Stal O, Thorstenson S, et al. Pathology parameters and adjuvant tamoxifen response in a randomised premenopausal breast cancer trial. J Clin Pathol. 2005;58(11): $1135-42$.

25. Elston CW, Ellis IO. Pathological prognostic factors in breast cancer. I. The value of histological grade in breast cancer: experience from a large study with long term follow-up. Histopathology. 1991;19(5):403-10.

26. Nadji M, Gomez-Fernandez C, Ganjei-Azar P, Morales AR. Immunohistochemistry of estrogen and progesterone receptors reconsidered: experience with 5,993 breast cancers. Am J Clin Pathol. 2005; 123(1):21-7.

27. Hefti MM, Hu R, Knoblauch NW, Collins LC, Haibe-Kains B, Tamimi RM, et al. Estrogen receptor negative/progesterone receptor positive breast cancer is not a reproducible subtype. Breast Cancer Res. 2013;15(4):R68.

28. Sobral-Leite M, Salomon I, Opdam M, Kruger DT, Beelen KJ, van der Noort V, et al. Cancer-immune interactions in ER-positive breast cancers: PI3K pathway alterations and tumor-infiltrating lymphocytes. Breast Cancer Res. 2019;21(1):90.

29. Thomas A, Routh ED, Pullikuth A, Jin G, Su J, Chou JW, et al. Tumor mutational burden is a determinant of immune-mediated survival in breast cancer. Oncolmmunology. 2018;7(10):e1490854.

30. National Institute for Health and Care Excellence (NICE). Tumour profiling tests to guide adjuvant chemotherapy decisions in early breast cancer. 2018. https://www.nice.org.uk/guidance/dg34. Accessed 11 June 2020.

31. Andre F, Ismaila N, Henry NL, Somerfield MR, Bast RC, Barlow W, et al. Use of biomarkers to guide decisions on adjuvant systemic therapy for women with early-stage invasive breast cancer: ASCO Clinical Practice Guideline updateintegration of results from TAILORx. J Clin Oncol. 2019;37(22):1956-64. 
32. Blok EJ, Engels CC, Dekker-Ensink G, Meershoek-Klein Kranenbarg E, Putter $\mathrm{H}$, Smit VTHBM, et al. Exploration of tumour-infiltrating lymphocytes as a predictive biomarker for adjuvant endocrine therapy in early breast cancer. Breast Cancer Res Treat. 2018;171(1):65-74.

\section{Publisher's Note}

Springer Nature remains neutral with regard to jurisdictional claims in published maps and institutional affiliations.

Ready to submit your research? Choose BMC and benefit from:

- fast, convenient online submission

- thorough peer review by experienced researchers in your field

- rapid publication on acceptance

- support for research data, including large and complex data types

- gold Open Access which fosters wider collaboration and increased citations

- maximum visibility for your research: over $100 \mathrm{M}$ website views per year

At $\mathrm{BMC}$, research is always in progress.

Learn more biomedcentral.com/submissions 